\title{
Effect of $\mathrm{ZrO2}$ Addition on Microstructure and Mechanical Properties of Al-Zn-Mg Alloy Matrix Composite
}

\author{
Israa A. Aziz ${ }^{\mathbb{a}^{*}}{ }^{*}$, Russul S. Bedien ${ }^{\mathrm{b}}$ \\ ${ }^{a}$ Production Eng. \& Metallurgy Department, University of Technology, Baghdad, Iraq, \\ 70014@uotechnology.edu.iq. \\ ${ }^{\text {b }}$ Production Eng. \& Metallurgy Department, University of Technology, Baghdad, Iraq, \\ Russul_sadeq@yahoo.com. \\ *Corresponding author.
}

Submitted: 02/06/2019

Accepted: 24/07/2019

Published: 25/12/2020

\section{K E Y W O R D S}

Stir Casting, Composite

Materials,

Microstructure,

Mechanical Properties.

\begin{abstract}
A B S T R A C T
Aluminum - based metal matrix composite are widely used in industrial applications compared with conventional and unreinforced alloy. The composite materials usually exhibit a higher strength both at elevated and ambient temperature, as well as wear resistance. The production of composite materials which contain different weight percentage of $\mathrm{ZrO}_{2}$ $(0.5,1.5$ and $2.5 \mathrm{wt} \%)$ by stir casting process. The mechanical properties of the base alloy and composite were evaluated by using tensile and hardness tests. The microstructure inspection by optical microscopy, scanning electron microscope and energy dispersive spectroscopy (EDS) were utilized to study the fracture surface topography. The results represent that the hardness, strength of yield and tensile strength increased with increasing the weight \% of $\mathrm{ZrO} 2$ to $2.5 \%$ while the elongation decreased. The microstructure inspection by optical microscope shows that the dendrites structure and the particles distribution in matrix without any voids. Furthermore, the grain size refining with the weight percentage of weight reinforcement elevated.
\end{abstract}

How to cite this article: I. A. Aziz and R. S. Bedien, "Effect of Addition $\mathrm{ZrO}_{2}$ on Microstructure and Mechanical Properties of AlZn-Mg Alloy Matrix Composite,” Engineering and Technology Journal, Vol. 38, Part A, No. 12, pp.1751-1757, 2020.

DOI: https://doi.org/10.30684/etj.v38i12A.336

This is an open access article under the CC BY 4.0 license http://creativecommons.org/licenses/by/4.0

\section{INTRODUCTION}

The new applications of industrial engineering require advanced materials improvements by lowering the thermal expansion coefficient, production of high thermal stability at high temperatures for engine components, best wear resistance, high specific stiffness, and satisfactory corrosion resistance in defense applications $[1,2]$. The composites material contains a nonmetallic reinforcement $\left(\mathrm{SiC}, \mathrm{B}_{4} \mathrm{C}, \mathrm{TiC}, \mathrm{TiB}_{2}\right.$, $\mathrm{ZrO}_{2}, \mathrm{WC}, \mathrm{Al}_{2} \mathrm{O}_{3}, \mathrm{TiO}_{2}$, etc.) matrix which produce beneficial properties than base metal aluminum alloy [3]. Most composite materials reinforced with particles by liquid metallurgy method or so called stir casting process which gives excellent properties over traditional methods, as its simple, inexpensive, good binding to matrix, and flexibility control of composition. Numerous studies and researchers have been 
working in this field. Madhusdhn et al. 2016 [4] studied the effects of $\mathrm{ZrO}_{2}$ p reinforcement addition on mechanical properties "hardness "and resistance of wear for Al-7075 and its composites using varying weight percentage $0-8 \mathrm{wt} \%$ the composite manufacturing by stir casting. The results present best value in" hardness", friction coefficient, good strength and lowering wear rate with increasing the weight percentage of reinforcement particles additions. Sunil Kumar K K A and D.P. Girish [5] , investigate the influence of cenosphere content was varied from 2 to $6 \mathrm{wt} \%$ and short E-glass fibers are varied from 1 to $5 \%$ in steps of $2 \%$ by weight in the composites. The stir casting method was used to produce the composites by adding cenosphere particles to Al-7075alloy. The results represent increasing in specific modulus, specific strength, damping capacity and good wear resistance when compared with base alloy. The aim of this research is to study the changes in microstructure \& mechanical properties by adding $\mathrm{ZrO}_{2}$ particulate reinforcement with different weight percent $(0.5,1.5$, and $2.5 \%)$ on the microstructure and mechanical properties of alloy Al-Zn-Mg.

\section{EXPERIMENTAL WORK}

In this experimental work, particulate $\mathrm{ZrO}_{2}$ additions as reinforcement with particle size vary between (50-75) $\mu \mathrm{m}$ embedded in Al-Zn-Mg alloy as a matrix. Table I demonstrates the chemical composition of the base alloy. The Al-Zn-Mg alloy was melted in alumina crucible at $750{ }^{\circ} \mathrm{C}$ in a local electrical furnace that is preheated at $300{ }^{\circ} \mathrm{C}$ for one $\mathrm{hr}$ in a steel mold, and then pour into a mold to prepare the base alloy. The composites have been produced by stir casting process where it was melting the base alloy at 750 ${ }^{\circ} \mathrm{C}$, which is above the liquid's temperature composition for the melt at this temperature for 15 min., then added flux $1 \mathrm{wt} \% \mathrm{NaF}_{2}$.

TABLE I: Analysis of the chemical content for alloy Al-Zn-Mg .

\begin{tabular}{cc}
\hline \hline Element & Wt \% \\
\hline $\mathrm{Si}$ & 0.0949 \\
$\mathrm{Fe}$ & 0.221 \\
$\mathrm{Cu}$ & 1.38 \\
$\mathrm{Mn}$ & 0.0261 \\
$\mathrm{Mg}$ & 2.31 \\
$\mathrm{Cr}$ & 0.191 \\
$\mathrm{Zn}$ & 5.88 \\
$\mathrm{Ti}$ & 0.0278 \\
$\mathrm{Al}$ & $\mathrm{Bal}$ \\
\hline
\end{tabular}

The reinforcing materials $\mathrm{ZrO}_{2}$ gradually adding to molten base alloy with different percentages $(0.5$, 1.5 , and $2.5 \mathrm{wt} \%$ ) were they wrapped by foil of aluminum and preheated at $550{ }^{\circ} \mathrm{C}$ for one hour to remove the moisture, and to help the wettability improvement of particles with matrix Al-Zn-Mg alloy. The melt alloy stir by electric stirrer with rotational speed 750 RPM so as to produce suitable dispersion for reinforcement in base alloy. Magnesium has been added with $1 \mathrm{wt} \%$ to improve the wettability. Then, the molten pouring in the mold and the process is repeated gradually for all additions. The base alloy and composites prepared for examination process by machining. The turning process used to produce the specimen with dimension $15 \times 10 \mathrm{~mm}$. The samples then grinding with silicon carbide papers 500 and 1000 grit, after then used cloth " $5 \mu \mathrm{m}$ and $0.3 \mu \mathrm{m}$ " alumina suspension consequently for polishing. These samples were then washed by water, alcohol and dried by hot air. The micro hardness measured by Vickers hardness apparatus. The load used was $200 \mathrm{~g}$. The samples for microstructure examination after etching by solution which contain $1 \% \mathrm{HF}$ and $99 \% \mathrm{H}_{2} \mathrm{O}$ [6], then washed by water, alcohol and dried by hot air. The grain size measured by standard method ASTM using mean linear intercept method [7]. The tensile test has been proceeded for the sample produced by using ASTM E8 [8], as presented in Figure 1, then the tensile test fracture surface inspection by SEM. 


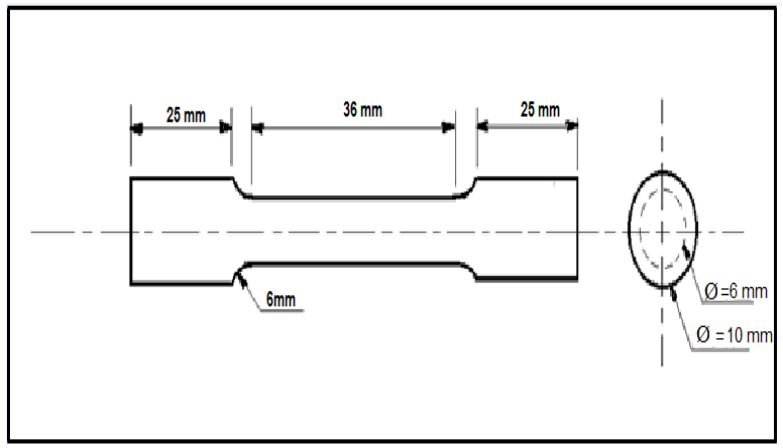

Figure 1: Standard tensile test specimen [8].

\section{RESULTS AND DISCUSSION}

\section{Examination of the Microstructure}

The examination of microstructure by using optical microscope with digital camera. Figure 2 represent the microstructure of base alloy which have dendrite shape. Figure 3 shows the microstructure dendrites shape of $\alpha$-Al and the particulate reinforcement's coalescence also spread into the matrix at any location. Also, the results of grain size measurement show that the grain size decreases with elevating the wt $\%$ of $\mathrm{ZrO}_{2}$, as shown in Table II, because the reinforcement particles leads to produce a heterogeneous nucleation sites and hindered the grain growth [9]. These particles coalescence then distribution into the matrix at any space also the grain size decreases with increasing the addition of reinforcing particles.

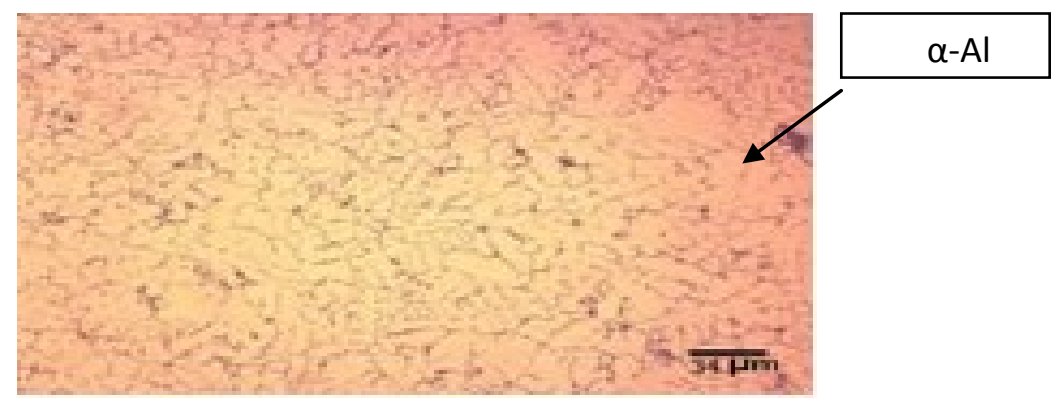

Figure 2: The microstructure of base alloy.

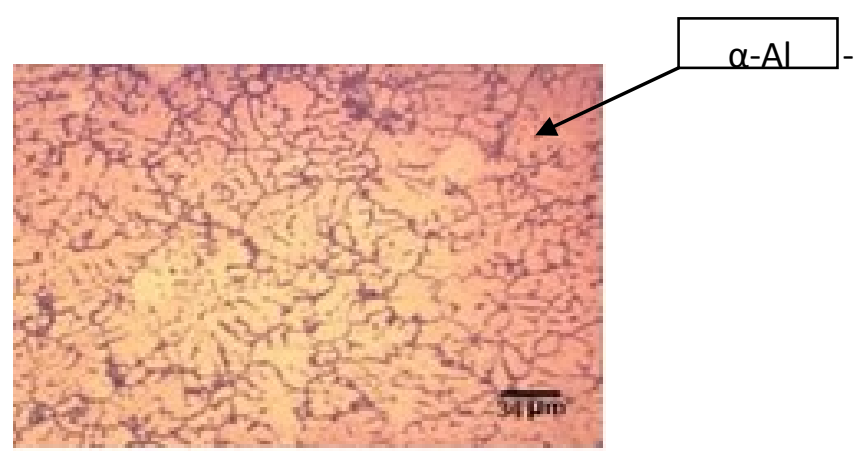

(a) 


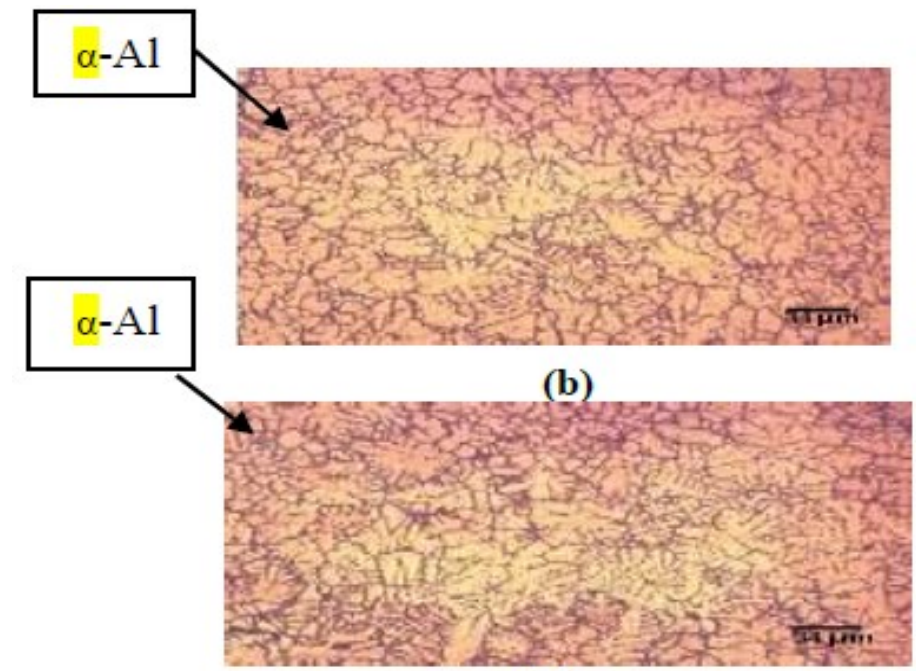

(c)

Figiure3: Microstructure of composites, (a-0.5 wt\%, b-1.5 wt \%, c-2.5 wt \%) $\mathrm{ZrO}_{2}$.

TABLE II: Grain size measurment by ASTM

\begin{tabular}{ccccc}
\hline \hline $\mathbf{W t}_{\mathbf{2}} \mathrm{ZrO}_{2}$ & 0 & 0.5 & 1.5 & 2.5 \\
\hline Grain size mm & 0.833 & 0.732 & 0.476 & 0.4 \\
\hline
\end{tabular}

\section{II.Tensile test}

Figures 4 (a) and (b) demonstrates the mechanical properties of composites, tensile ultimate strength and strength of yield of composites are higher than the base alloy, but the percentage of elongation decreases as present in Figure 4-c. This is due to the nature of the hardned $\mathrm{ZrO}_{2}$ particles embeded in the composite which produce good bonding between the matrix and particles .

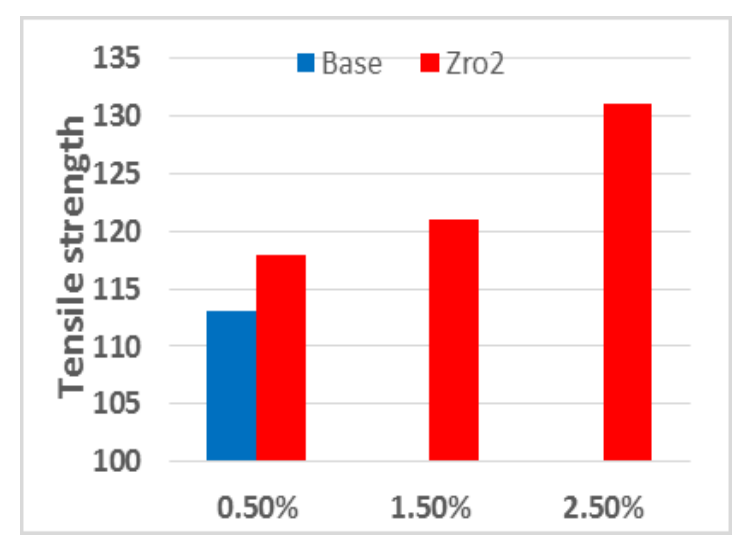

(a) 


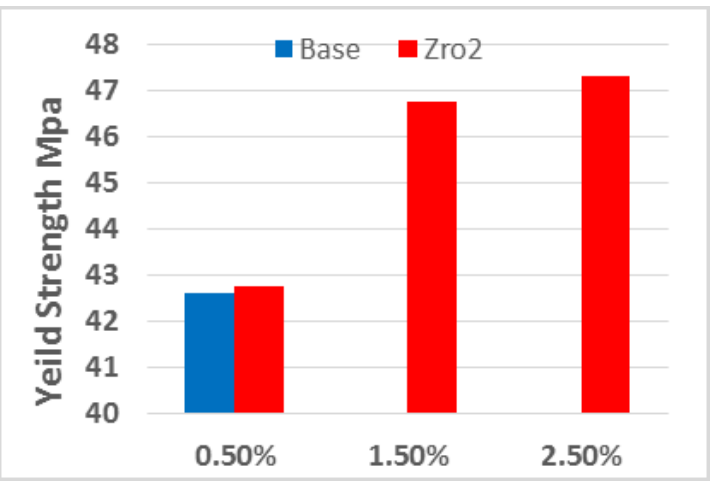

(b)

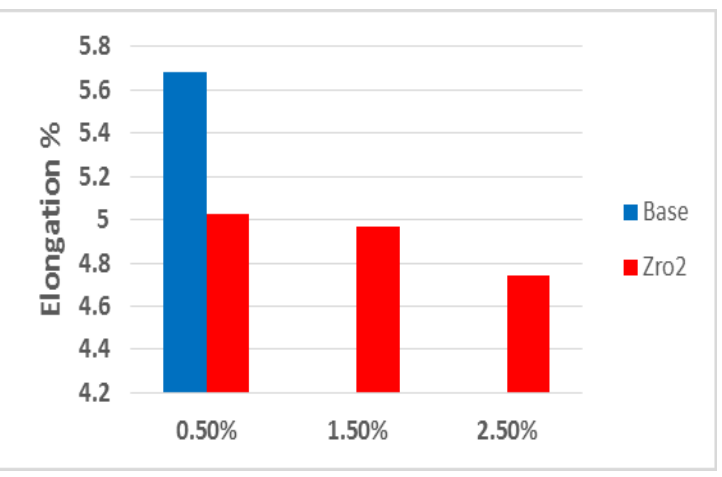

(c)

Figure 4: Relationship between (a) Tensile ultimate strength (b) Strength of yield and (c) \% of elongation with $\%$ of reinforcement for the base alloy.

The grain refining increases the strength of composite materials according to Hall-Pitch equation [9].The addition of reinforcement particles also improves the tensile strength and effective fracture by transferring stress from the Al-matrix to reinforcement particles, because the Orwan mechanism play an important rule which a dislocation passes through the heavy obstacles when restricting the dislocation around $\mathrm{ZrO}_{2}$ particles. It could be seen that elongation decreases due to ceramic particles increasing the hardness. Figures 5 shows the elemental mapping represent the $\mathrm{ZrO}_{2}$ particles distribution in a matrix.
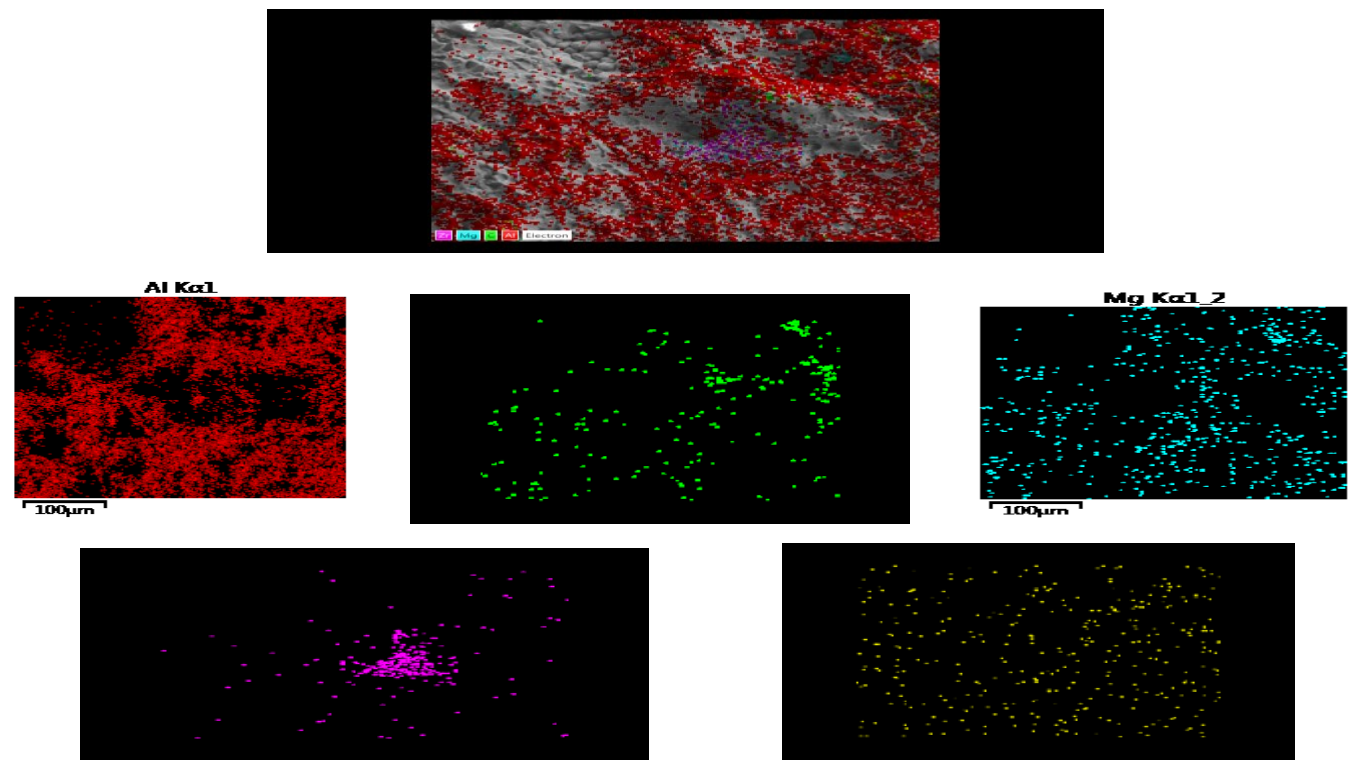

Figure 5: SEM, elemental mapping of $2.5 \% \mathrm{ZrO}_{2}$ composite. 


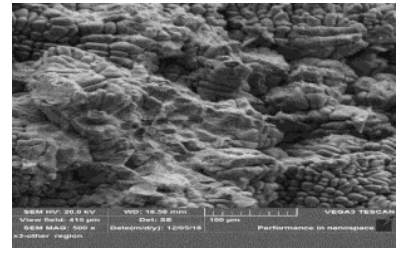

( a )
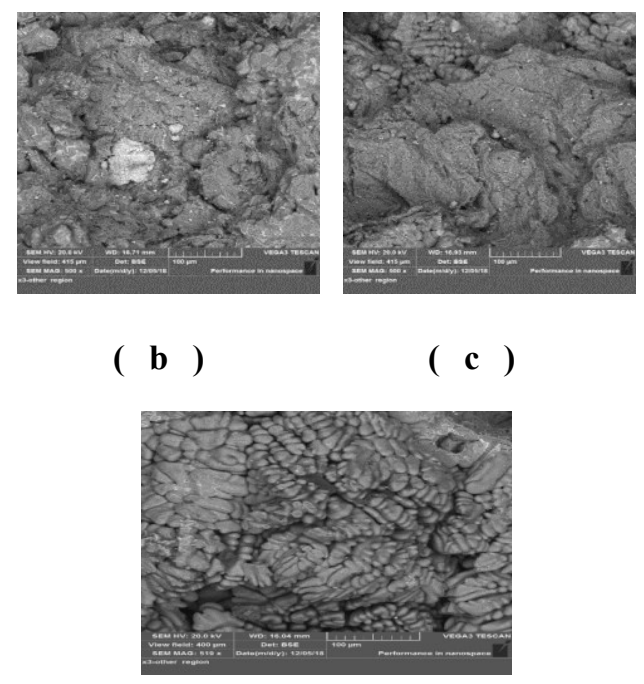

(d)

Figure 6: Fracture surface using, SEM, (a) as cast, (b) $0.5 \% \mathrm{ZrO}_{2}$, (c) $1.5 \% \mathrm{ZrO}_{2}$, (d) $2.5 \% \mathrm{ZrO}_{2}$

\section{Hardness Test}

Figure 7 shows the relationship between the grain size and hardness of the base alloy and composites. This observation shows that the composite hardness increased with decreasing the grain size because the $\mathrm{ZrO}_{2}$ particles are working to refining grains and also increased strength such as present by Hall Petch equation [9]. Figure 8 represent the relation between the hardness and the weight percentage of reinforcement particles. It is observed that the hardness increased with increasing the addition of $\mathrm{ZrO}_{2}$ particles, because these particles impeded in the matrix and causes a large obstruction to the dislocations movement [10].

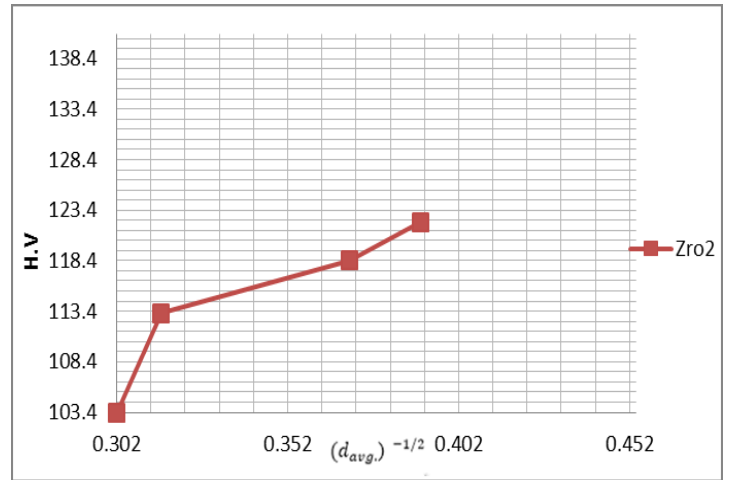

Figure 7: Relationship between hardness and grain size. 


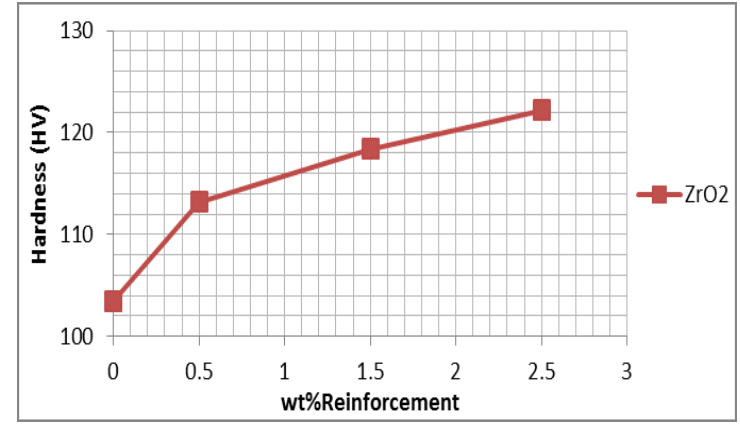

Figure 8: Relationship between hardness and reinforcements.

\section{CONCLUSIONS}

1. The microstructure of the composite after the addition of zirconium oxide particles were changes to dendrite structure.

2. The hardness increased with increasing the weight percent of $\mathrm{ZrO}_{2}$ additions.

3. The strength of ultimate tensile and strength of yield elevated with increasing the $\mathrm{wt} \%$ of $\mathrm{ZrO}_{2}$ particles addition.

4. The increasing of $\mathrm{wt} \% \mathrm{ZrO}_{2}$ additions produced lower elongation.

\section{ACKNOWLEDGEMENT}

I would like to thank the head of the Production Engineering and Metallurgy Department at the University of Technology, Baghdad for their financial support and assistance in this research study.

\section{References:}

[1] J. J. Rino, D. Chandramohan and V.D. Jebin, "Research review on corrosion behavior of metal matrix composite", International Journal of Current Research, Vol.4, No.9, pp.179-186, 2012.

[2] P. O. Babalola, C. A. Bolu, A.O. Inegbenebor and K. M. Odunfa, "Development of aluminum matrix composites: A review", International Journal of Engineering and Technology Research, Vol.2, pp.1-11, 2014.

[3] H. N. Reddappa, K. R. Suresh, H. B. Niranjan, and K.G. Satyanarayana, "Studies on mechanical and wear properties of $\mathrm{Al} 6061$ composite", Journal of Minerals and Materials Characterization and Engineering ,Vol.11, pp.704-708, 2012.

[4] M. Madhusudhan, K. N. Vikram, K. Mahesha and B. Chandra, "Evaluation of microstructure and mechanical properties of As cast Al-alloy 7075 and $\mathrm{ZrO}_{2}$ dispersed metal matrix composites", International Journal of Mechanical and Production Engineering, Special Issue, pp.93-99, 2016.

[5] K. A. Sunil Kumar and D.P.Girish, "Study and evaluation of mechanical properties of Al7075 / cenosphere /Eglass metal matrix composites", International Journal of Research ", Vol.VIII, Issue I, pp.1-16, 2019.

[6] W. Perrin and H.T. Williiam, "Handbook of metal etchants", CRC press, $1^{\text {st }}$ edition, New York, 1991.

[7] "Standard Test Method for Determining Average Grain Size", ASTM E112, Annual Book Standards, Vol.3.01, 2013.

[8] "Standard test method for tension testing of metallic materials", AASTO, No.T68 American Association State, Highway and Transportation Official standard, American National Standard, 2012.

[9] M. Sambathkumar, P. Navaneethakrishnan, K. Ponappa, and K.S.K , Sasikumar, "Mechanical and corrosion behavior of A17075 (hybrid) metal matrix composites by two step stir casting process", Latin American Journal of Solids and Structures, Vol.14, No.2, pp.243-255, 2017.

[10] G. B. Veeresh Kumar, C.S.P.Rao, N.Selvaraj and M.S. Bhagyashekar", Studies on Al6061-SiC and Al7075$\mathrm{Al}_{2} \mathrm{O}_{3}$ metal matrix composites", Journal of Minerals \& Materials Characterization \& Engineering, Vol.9, No.1, pp.43-55, 2010. 